\title{
The Outbound Containers' Storage Location Assignment Problem for a Maritime Terminal
}

\author{
Ercan Şenyiğit ${ }^{*}$, Murat Suat Arsav ${ }^{2}$ \\ ${ }^{1}$ Erciyes Üniversitesi, Mühendislik Fakültesi, Endüstri Mühendisliği Bölümü, Kayseri, Türkiye (ORCID: 0000-0002-9388-2633) \\ ${ }^{2}$ Erciyes Üniversitesi, Mühendislik Fakültesi, Endüstri Mühendisliği Bölümü, Kayseri, Türkiye (ORCID: 0000-0003-0087-7956)
}

(This publication has been presented orally at HORA congress.)

(First received 1 August 2019 and in final form 25 October 2019)

(DOI: $10.31590 /$ ejosat.638305)

\begin{abstract}
ATIF/REFERENCE: Şenyiğit, E. \& Arsav, M. S. (2019). The Outbound Containers' Storage Location Assignment Problem for a Maritime Terminal. European Journal of Science and Technology, (Special Issue), 349-355.
\end{abstract}

\begin{abstract}
Seaway is important for supply chain management in order to be carried for manufactured products and logistics activities. However, this logistics process does not only consist of transportation. Storing transported goods temporarily or permanently in ports according to an appropriate plan is vital in order to whole process is carried on properly. This paper describes the storage location assignment problem for outbound containers in a maritime terminal and hybrid sequence stacking algorithm (HSSA) which is used to solve this problem. In this problem; yard bay consists of 6 horizontally and 4 vertically units long (6x4) totally 24 units of squares. 18 containers which are come in random weight and sequence are wanted to be placed into these slots optimal. Considering the fact that ships are loaded first with the heaviest containers and then with lighter containers; the presence of lightweight containers in the upper spaces necessitates a rehandle operation for the lightweight containers above to reach heavy containers. The main purpose of our method is to minimize the number of rehandle operations. For this purpose, according to the basic logic of HSSA algorithm; the heaviest containers are tried to be placed on the top and leftmost slots, on the other hand the lightest containers are tried to be placed on the bottom and rightmost slots as much as possible. However, the fact that incoming containers come at different weights in a different number and in a previously unknown sequence is the biggest obstacle to this method always achieving the best solution. At this point, although the method is a heuristic algorithm, it is important that it gives satisfactory results. In this study, a sample was solved by using HSSA and the results were presented in the study. These results show that the proposed algorithm is effective and efficient in solving the storage location assignment problem.
\end{abstract}

Keywords: Maritime terminal, Container, Storage location assignment, Hybrid Sequence Stacking Algorithm, Heuristics.

\section{Bir Deniz İstasyonunda Dışarı Giden Konteynerler için Depolama Konumu Atama Problemi}

$\ddot{O} \mathbf{z}$

Deniz yolu, üretilen ürünlerin taşınması ve lojistik faaliyetleri gibi tedarik zinciri yönetiminde önemli bir yere sahiptir. Ne var ki, buradaki lojistik süreci sadece taşımadan ibaret değildir. Taşınan ürünlerin limanlarda uygun bir plana göre geçici veya kalıcı olarak depolanması bütün sürecin sağlıklı bir şekilde işleyebilmesi açısından hayati bir öneme sahiptir. Bu makale, bir deniz istasyonunda dışarı giden konteynerler için depolama konumu atama problemini ve bu problemin çözümü için kullanılan hibrit dizi istifleme algoritmasını (HDİA) anlatmaktadır. Üzerinde çalışılan problemde; yatayda 6, dikeyde 4 birim uzunluğundaki (6x4) toplamda 24 birim kareden oluşan boş yere sahip bir tersane iskelesine yerleştirilmek üzere rasgele ağırlık ve sırada gelen 18 konteynerin bu boşluklara en uygun şekilde yerleştirilmesi dikkate alınmaktadır. Gemilere öncelikle en ağır olan konteynerlerin sonrasında ise daha hafif olan konteynerlerin yüklendiği bilgisi göz önüne alındığında; üstteki boşluklarda hafif konteynerlerin yer alması ağır konteynerlere ulaşmak

${ }^{*}$ Corresponding Author: Erciyes Üniversitesi, Mühendislik Fakültesi, Endüstri Mühendisliği Bölümü, Kayseri, Türkiye, ORCID: 0000-0002-9388-

2633, senyigit@erciyes.edu.tr 
amacıyla üstteki hafif konteynerler için yeniden taşıma operasyonunu gerekli kılar. Uyguladığımız yöntemin temel amacı yeniden taşımayı operasyonu sayısını minimize etmektir. Bu amaçla HDİA algoritmasının temel mantığına göre en ağır olan konteynerler; olabildiğince en üst ve en sol taraftaki boşluklara, en hafif olan konteynerler; olabildiğince en alt ve en sağ taraftaki boşluklara yerleştirilmeye çalışılır. Fakat gelen konteynerlerin farklı ağırlıklarla farklı sayıda ve önceden sırası bilinmeyen bir dizide rasgele olarak gelmesi bu yöntemin her zaman en iyi çözümü elde etmesinin önündeki en büyük engeldir. Bu noktada yöntemin sezgisel bir algoritma olmasına rağmen tatmin edici sonuçlar vermesi önemlidir. Bu çalışmada HDİA kullanılarak bir örnek çözülmüş ve elde edilen sonuçlar çalışmada sunulmuştur. Bu sonuçlar önerilen algoritmanın depolama konumu atama probleminin çözümünde etkili ve verimli olduğunu göstermektedir.

Anahtar Kelimeler: Deniz İstasyonu, Konteyner, Depolama Konumu Atama, Hibrit Dizi İstifleme Algoritması, Sezgiler.

\section{Giriş}

Bir konteyner istasyonun küresel ulaşım ağında birden fazla ara yüzü vardır. Konteynerler deniz ve kara taşıyıcıların varış zamanlarındaki farklılıkları açıklamak için geçici olarak depolanırlar. Gelen konteynerler için depolama konumu ataması konteyner taşımacılığının verimliliğinin geliştirilmesi ve bir geminin etrafta dolaşma süresinin azaltılması açısından önemlidir. Gelen ve giden konteyner operasyonları farklıdır. Gelen konteynerler tersaneye tahminen büyük yığınlar halinde ulaşırlar, ama tersaneden talep edildiklerinde birer birer tahmin edilemeyen sıralarda yola çıkarlar. Limandan ayrılan konteynerler tahmin edildiği gibi yola çıkarlar ama rasgele bir sırada varış yaparlar. Onlar, gemilerin kararlılığını sağlayabilmek ve yükleme gereksinimini karşılayabilmek için -bu durum varış yeri ve konteynerlerin boyutu(büyüklügü) ile belirtilir- katı bir depolama planına göre yüklenmelidir. Bu çalışma giden konteynerlerin istiflenmesinde operasyonel karar verme problemine üzerine odaklanmaktadır. Bu çalışmada, deniz istasyonundan dışarı giden konteynerler için depolama konumu belirlenmesi amacıyla sistematik bir yaklaşım getirilmiştir. Burada en önemli amaç ise; yeniden taşıma operasyonlarının minimize edilmesi, böylece yükleme operasyonlarında maksimum verim elde etmektir. Yeniden taşıma, diğer konteynerin erişimine izin vermek için yapılan bir konteyner hareketidir ve verimsiz bir hareket olarak kabul edilir. Biz tersane vinçlerinin ve kamyonların konteyner taşıma aracı olarak tersanede kullanıldıklarını varsayıyoruz. Dışarıdaki bir kamyon dışarıya giden bir konteyneri tersaneye teslim ettiğinde, bir tersane vinci onu toplar ve onu tersane iskelesine yığar. Yükleme operasyonu süresince bir tersane vinci konteyneri toplar ve onu bir tersane kamyonunun üzerine onu iskele vincine transfer etmesi için koyar. Bir istasyonda yüklenen her bir gemi bir depolama planına sahiptir. Nakliye hattı istasyona gönderilmek üzere konteyner kategorilerine dayanılarak kabataslak bir plan yapar. Gemilerin gelişinden önce, istasyon planlayıcısı tarafından kategorileri detaylı konteynerlerle dolduran daha detaylı bir plan yapılır. Bu depolama planı depolama tersanesindeki hangi konteynerin hangi konumda gemiye yükleneceğini belirtir. Çalışmada iki ana amaç bulunmaktadır. Bu amaçlar şunlardır: (1) geminin kararlılığını sağlamak ve (2) iskele vinçlerinin ve tersane araçlarının taşımak için harcadığı çabayı minimize etmektir. Depolama tersanesinin içinde konteynerler bloklar içerisinde depolanır. Her bir blok dört veya beş konteyner yüksekliğindeki 20-30 tersane iskelesinden meydana gelir. Her bir tersane iskelesi yan yana altı sıraya sahiptir (Şekil 1'e bakınız). Normalde, dışarı giden konteynerler yüklemeyi beklemek için gemilerin yola çıkışından 3-4 gün önce istasyona gelmeye başlarlar. Verimli bir yükleme sıralamasına sahip olmak için, dışarı giden konteynerler en uygun konumlara yerleştirilmelidir. Ancak, depolama tersanesindeki dışarı giden konteynerlerin ideal yerleşiminin gerçekleşmesi konteynerlerin istasyona rasgele gelmesinden dolayı neredeyse imkânsızdır. Konteynerleri varış yeri ve ağırlıklarına göre gruplamak amacıyla yüklemenin öncesinde konteyner karıştırma yükleme operasyonlarının verimliliğini artırmak için bir yoldur.

Ancak, bu görev ekipmanları taşımak için ekstra iş yükü gerektirmektedir. Bu nedenle, konteyner karıştırma sadece ekipmanların taşınması boştayken uygulanabilir. Ek olarak; karıştırma, tampon bir yığma alanı gerektirir ki bunun da pratik ve gerçekçi olarak karadaki kıt konteyner istasyonlarında uygulanması hemen hemen mümkün görünmez. Bundan dolayı, dışarı giden konteynerler için depolama konumu saptama, yükleme operasyonlarının üretkenliğini artırmak adına hayati bir öneme sahip olur. Bu aşamada konteynerler, konteyner ağırlıklarına dayanarak çeşitli ağırlık gruplarına kategorize edilirler. Tersane iskelesinde farklı ă̆ırlık gruplarındaki konteynerlerin farklı düzenlemeleri göz önüne alarak, önceden atanmış bir tersane iskelesinde bir ağırlık grubundaki gelen bir konteynerin depolama yerini belirlemek için literatürde bir yöntem önerilmiştir (Chen ve Lu, 2012). Bu yöntemin amacı yükleme operasyonları süresince beklenen tekrar taşıma sayısını minimize etmektir. Belirli bir tersane iskelesinin içinde ağır konteynerlerin hafif konteynerlerden önce yüklendiği varsayılır. Genel olarak, ağır konteynerlerin daha erken yüklenmesi olasıdır. Bundan dolayı, eğer ağır konteynerler tersane iskelesinde daha alt aşamalarda konumlandırılıyorlarsa, yeniden taşıma operasyonları muhtemelen meydana gelecektir. Bu varsayım altında, yeniden taşıma operasyonlarını minimize etmek makuldür (Chen ve Lu, 2012).

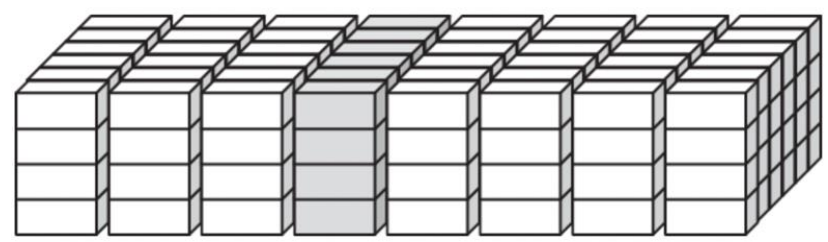

Tersane iskelesi 
Şekil 2 yığma dizisinde bir iskele farklı düzenlemeleri gösterilmektedir. Her bir boşluktaki sayı, boşlukta yığılmış konteynerlerin ağrılık seviyesini temsil eder. Daha büyük sayı, daha büyük ağırlık seviyesi demektir. Dikey istifleme ve yatay istiflemede sırasıyla beş ağırlık seviyeleri ve dört ağılık seviyeleri dikkate alınır. Boşluklar her iki durumda da istifleme tamponları olarak rezerve edilir. Konteynerlerin dizisinin rasgele gelişinden dolayı, Şekil 2'de gösterilen ideal iskele düzenlenmesini elde etmek zordur. Normalde, istifleme sürecinde çok fazla yeniden taşıma operasyonuna ihtiyaç duyulur. Örneğin, Şekil 2(a)'da gösterilen dikey istifleme için, eğer çok fazla ağır konteyner ilk olarak tersaneye gelirse, o zaman kamyon şeridinin yanındaki yığın dolu olacaktır. Bundan dolayı, tersane vincinin hareketi gelen hafif konteynerlerin istiflenmesi için zor olacaktır. Şekil 2(b)'de gösterilen yatay istifleme için, eğer ağır bir konteyner ilk olarak tersaneye varırsa, tampon boşluğa yerleştirilmek zorunda kalır ve hafif konteynerler vardığında yeniden karıştırma gerektirir (Chen ve Lu, 2012).

a

\begin{tabular}{l|c|c|c|c|c|c|}
\hline & 5 & 4 & 3 & 2 & 1 \\
\cline { 2 - 6 } \multirow{4}{*}{$\begin{array}{l}\text { Kam } \\
\text { yon } \\
\text { şeridi }\end{array}$} & 5 & 4 & 3 & 2 & 1 \\
\cline { 2 - 6 } & 5 & 4 & 3 & 2 & 1 \\
\cline { 2 - 6 } & 5 & 4 & 3 & 2 & 1 \\
\hline \multicolumn{6}{|c|}{ ikey istifleme }
\end{tabular}

b

\begin{tabular}{|c|c|c|c|c|c|}
\hline \multirow{4}{*}{$\begin{array}{l}\text { Kamy } \\
\text { on } \\
\text { şeridi }\end{array}$} & 4 & 4 & 4 & 4 & 4 \\
\hline & 3 & 3 & 3 & 3 & 3 \\
\hline & 2 & 2 & 2 & 2 & 2 \\
\hline & 1 & 1 & 1 & 1 & 1 \\
\hline
\end{tabular}

Şekil 2: Dizi istiflemesi (Chen, 2012)

Zhang ve diğerleri (2003) istasyonun depolama tersanesinde depolama alanı paylaştırma problemini çalı̧̧ıı̧lardır. Gelen ve giden konteynerlerin her ikisi de göz önüne alınmış ve bunların bir blok olarak karıştırılmasına izin verilmiştir. Onlar alan paylaştırma problemini iki seviyeye ayırdılar. İlk seviyede, her bir depolama bloğuna yerleştirilecek toplam konteyner sayısı kararlaştırılır. İkinci seviyede, bloklar ve gemi yanaşma konumları arasında hareket eden konteynerlerin toplam taşıma mesafesini minimize etmek için her bir gemiye ait konteyner sayısı belirlenir. Çoğunlukla konum atama stratejileri gelen ve giden konteynerler için farklı şekilde değerlendirilir. Gelen konteynerler için, Castilho ve Daganzo (1992) depolama alanı atama için iki strateji sundular: ayrılmamış strateji ve ayrılmış strateji. Ayrılmamış stratejide, yeni ulaşan konteynerler var olanların en üstüne boş olan yerlere yerleştirilmek suretiyle onlar belirlenmiş seviyeyi doldurana kadar yı̆̆ı̆lır. Ayrılmış stratejide ise, yeni ithal edilen bir yığın konteynerinin yükü her bir gemiden boşalttığında, bir alan boşaltılır ve bölüştürülür. Ancak bu ayrıştırmanın faydası takas hareketi ihtiyacını karşılamalıdır. Gelen konteynerler için ayrıştırarak depolama stratejisini göz önüne alarak, Kim ve Kim (1999) en zor problemlerden birisinin tersane operasyonunda olduğunu düşündü, bu problem ki tersane vinçlerinin konteynerleri yeniden istenen konteynerlerin en üzerine taşınması için çok fazla taşıma çabası harcanmasına yol açıyordu. Yazarlar konteyner yığınlarının yüksekliği ve yeniden taşıma sayılarının arasındaki ilişkiyi tanımlayan bir formül geliştirdiler. Kim ve Park (2003) giden konteynerler için depolama konumlarının belirleme sürecini iki aşamaya ayırmıştır: alan bölüştürme aşaması ve bireysel konteynerlerin konumlandırılması aşaması. Alan bölüştürme aşamasında, ileride dışarı gidecek konteynerler için her bir gemi için bölüştürülecek her bir bloğun alan miktarı belirlenir. Bireysel konteynerlerin konumlandırılması aşamasında, dışarı giden bir konteyner istasyona ulaştı̆ıında dışarı giden her bir konteyner için bir kesin depolama konumu için karar verilir. Yazarlar ilk aşamada alan paylaştırma problemini çözmek için amaç fonksiyonu konteynerlerin manevra alanı ve tersane arasındaki teslimat masraflarını minimize etmek ve dışarı giden konteynerlerin tersane alanı içinde belirli bir aralıkta toplanması amacıyla iskele vinçlerinin yolculuk masraflarının minimize edilmesi olan bir karma tam sayılı program geliştirdiler. Kim ve diğerleri (2000) yükleme operasyonları sırasında yeniden taşıma miktarını azaltmak amacıyla önceden atanmış bir tersane iskelesinde dışarı giden bir konteyner için depolama konumunu belirleyerek bireysel konteynerin konumlandırılması aşaması üzerine odaklandılar. Problemi çözmek için dinamik programlama kullanılır. Ancak, gelen konteynerler için bir tersane iskelesinin nasıl seçileceği her iki aşamada da belirtilmemiştir. Buna ek olarak konteynerlerin varış yeri bilgisi göz önüne alınmamıştır.

\section{Yöntem}

\subsection{Hibrit Dizi İstiflemesi}

Bu bölümde, gelen bir konteynerin keyfi bir şekilde düzenlenmesi verilen iskelenin bir tersanesindeki en iyi depolama konumunu belirlemek amacıyla bir hibrit dizi istiflemesi yöntemi literatürde sunulmuştur (Chen ve Lu, 2012) . Şekil 4 bir iskelenin hibrit dizi istiflemesindeki ideal bir düzenlemeyi göstermektedir. Benzer şekilde, her bir boşluktaki sayı, boşluk içinde istiflenmiş konteynerin ağırlık seviyesini temsil eder. Burada, konteynerler ağırlıklarına göre dokuz seviyeye bölünürler. Oklar konteynerlerin ağırlığının yönünde artı̧ıı gösterir. Bundan dolayı, bir iskelenin bu düzenlenmesinde, ağır konteynerler sol üst konumlarda istiflenirler ve hafif 
konteynerler sağ alt konumlarda istiflenirler. Aynı ağırlık seviyesinin konteynerleri bu düzenlemede aynı yı ̆̆ında veya aynı seviyede depolanmaz, bu durum depolama konumu belirlenirken daha fazla optimizasyon alanına izin verir. Bu prensiple ilgili diğer sebep şudur ki, tersane vinci için sol tarafı boş olan bir boşluktan bir konteyner toplamak her zaman daha kolaydır. Şekil 4'de iskele 9 kümeye ayrılır, bunların her biri karşılık gelen ağırlık seviyeleri ile konteynerler için optimal depolama konumlarını içerirler. Örneğin, seviye 6 için küme dört boşluğa sahiptir ki bunlar ağırlık seviyesi 6 olan konteynerler için optimal depolama konumlarıdır.

\subsubsection{Hibrit Dizi İstifleme Algoritması}

$\mathrm{Bu}$ bölümde yeni gelen bir konteynerin nereye koyulacağına karar vermek için bir hibrit dizi istifleme algoritması (HDİA) tanımlanır. HDİA'yı tanımlamak için aşağıdaki notasyonlar kullanılır (Chen ve Lu, 2012):
$\left[W_{\text {min }}, W_{\text {max }}\right]$
Konteynerlerin ağırlık aralığı
$W_{c}$
Konteyner c'nin ağırlığ
$L_{c}$
Konteyner c'nin ağırlık seviyesi
$i$
Ağırlık seviyesinin göstergesi[indeksi]
$S_{l}$
$l$ ağırlık seviyesi ile konteynerler için optimal boşluk kümesi
$\left(x_{1}, y_{1}\right)$
$S_{l}$ kümesindeki boşlukların geometrik merkezi
$\left(x_{c}, y_{c}\right)$
Konteyner c için en iyi depolama konumu
$\left(x_{c}^{S}, y_{c}^{S}\right)$
Konteyner c için Sl kümesine ait olmayan müsait depolama konumları

HDİA'yı sunmak için, biz iskeleyi Şekil 5'de gösterildiği gibi bir koordinat sistemine koyabiliriz. Her bir boşluk koordinat sistemindeki bir noktayı temsil etmektedir. Şekil 5 'den aşağıdakileri elde etmek kolaydır; $\left(x_{1}, y_{1}\right)=(6,1),\left(x_{2}, y_{2}\right)=(5.5,1.5),\left(x_{3}, y_{3}\right)=(5$, $2), \quad\left(x_{4}, y_{4}\right)=(4.5,2.5),\left(x_{5}, y_{5}\right)=(3.5,2.5),\left(x_{6}, y_{6}\right)=(2.5,2.5),\left(x_{7}, y_{7}\right)=(2,3),\left(x_{8}, y_{8}\right)=(1.5,3.5)$, ve $\left(x_{9}, y_{9}\right)=(1,4)(\mathrm{Chen}$ ve Lu, 2012).

\begin{tabular}{|c|c|c|c|c|c|c|}
\hline & 9 & 8 & 7 & 6 & 5 & 4 \\
\hline \multirow{3}{*}{$\begin{array}{c}\text { Kamyon } \\
\text { Şeridi }\end{array}$} & 8 & 7 & 6 & 5 & 4 & 3 \\
\hline & 7 & 6 & 5 & 4 & 3 & 2 \\
\hline & 6 & 5 & 4 & 3 & 2 & 1 \\
\hline
\end{tabular}

Şekil 4: Bir iskelenin ideal düzenlenmesi (Chen ve Lu, 2012)

HDİA yönteminin aşamaları Şekil 6'da gösterilmiş olup detaylar aşağıdaki adımlarda incelikle işlenmiştir:

Adım 1: Bir iskele seç: ilk aşamada önceden atanmış tersane iskeleleri arasından dolu olmayan ve sadece aynı varış yerinden gelen $c$ konteyneri ile bir tersane iskelesi seç; eğer böyle bir iskele bulunamazsa, gelen konteyner önceden atanmış boş bir iskelede istiflenir.

Adım 2: Ağırlık seviyesini elde et: gelen $c$ konteynerinin $W_{c}$ ağırlığını elde et, $c$ konteynerinin ağırlık seviyesi $L_{c}$ 'yi hesapla.

Adım 3: Optimal depolama boşluklarının kümesinde bir boşluk bul: optimal depolama boşluklarının kümesini $S_{L_{c}}$ 'yi elde et. $S_{L_{C}}$ 'de kullanılabilir boşluk varsa (boş yerlerin altındaki bütün boşluklar dolu olduğunda, boş bir boşluk "kullanılabilir" olarak adlandırılır), o zaman

(1) Rasgele müsait bir konum seç $\left(x_{c}, y_{c}\right)$;

(2) Konteyner $c$ 'yi $\left(x_{c}, y_{c}\right)$ 'de istifle;

(3) İskelenin düzenlenmesini güncelle;

(4) Adım 1'e git;

Aksi halde adım 4'e git. 
Adım 4: İskelede kalan kullanılabilir boş yerlerden bir boş yer bul: iskelede kullanılabilir olarak bulunan her $\left(x_{c}^{s}, y_{c}^{s}\right)$ boşluğu için aşağıdakileri yap

(1) $S_{L_{C}}$ 'nin geometrik merkezinden doğrusal mesafeyi,

$$
d_{s}=\left|X_{L_{c}}-X_{c}^{s}\right|+\left|y_{L_{c}}-y_{c}^{s}\right| \quad \text { denklemi ile hesapla }
$$

(2) Geometrik merkezden depolama konumu $\left(x_{c}, y_{c}\right)$ olacak şekilde minimum mesafe ile bir boşluk seç;

(3) Konteyner $c$ 'i $\left(x_{c}, y_{c}\right)$ 'de istifle;

(4) İskelenin düzenlenmesini güncelle;

(5) Adım 1'e git;

Adım 4(2)'de, çoklu konumların yukarıdaki değerlendirme fonksiyonu kullanılarak elde edinilmesi durumunda, optimal konum belirtilen kural kullanılarak seçilir. Ağır konteyner her zaman sol üst konumda istiflenir ve hafif konteyner her zaman sağ alt konumda istiflenir.

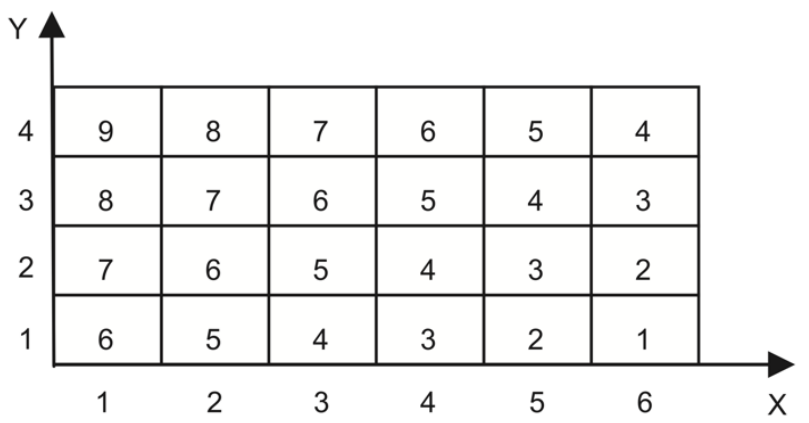

Şekil 5: Bir iskele koordinat sisteminin örnek gösterimi (Chen ve Lu, 2012)

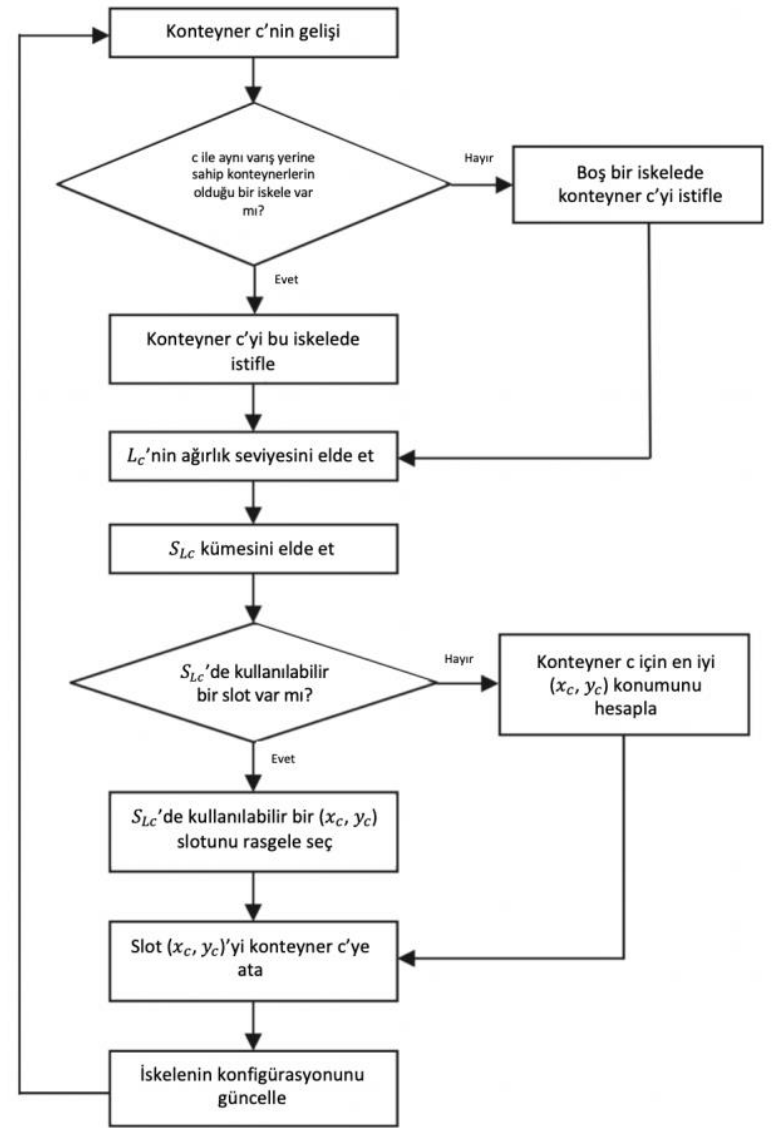

Şekil 6: HDIA süreci (Chen ve Lu, 2012) 


\section{Uygulama}

Çalışmada sunulan algoritmanın daha iyi anlaşılması için bir sayısal örnek oluşturulmuş ve bu örnek ile çözümü bir sonraki bölümde açıklanmıştır.

\subsection{Sayısal örnek}

HDİA’nın etkisini göstermek için burada nümerik bir örnek verilmiştir. Tersane iskelesi dört seviye ve altı şeride sahiptir. Biz dışarı giden 18 konteynerın gelen bir dizisini aynı istikamet limanı ile rasgele olarak ürettik. Diyelim ki konteynerler kendilerinin ağırlık seviyeleri ile ifade edilsin; bu konteynerlerin gelen dizisi (aynı zamanda istifleme dizisi): 3, 1, 3, 2, 5, 2, 4, 7, 4, 9, 8, 9, 7, 5, 6, 6, 1 ve 8'dir. 3, 1 ve 3 konteynerleri onların en uygun depolama boşluklarından birinde istiflenir. Her bir gelen konteyner için HDİA'nın uygulanması giriş bölümünde tanımlandı, her bir konteyner için depolama konumu Şekil 7'de gösterildi. Biz yüksek ağırlık seviyesindeki konteynerlerin düşük ağırlık seviyesindeki konteynerlerden daha önce yüklendiğini varsayıyoruz. Şekil 7'de verilen sayısal örnek hiç yeniden taşıma operasyonu yapılmadan çözüldü. Böylelikle belirtilen örnek için en iyi sonuç bulunmuştur diyebiliriz.

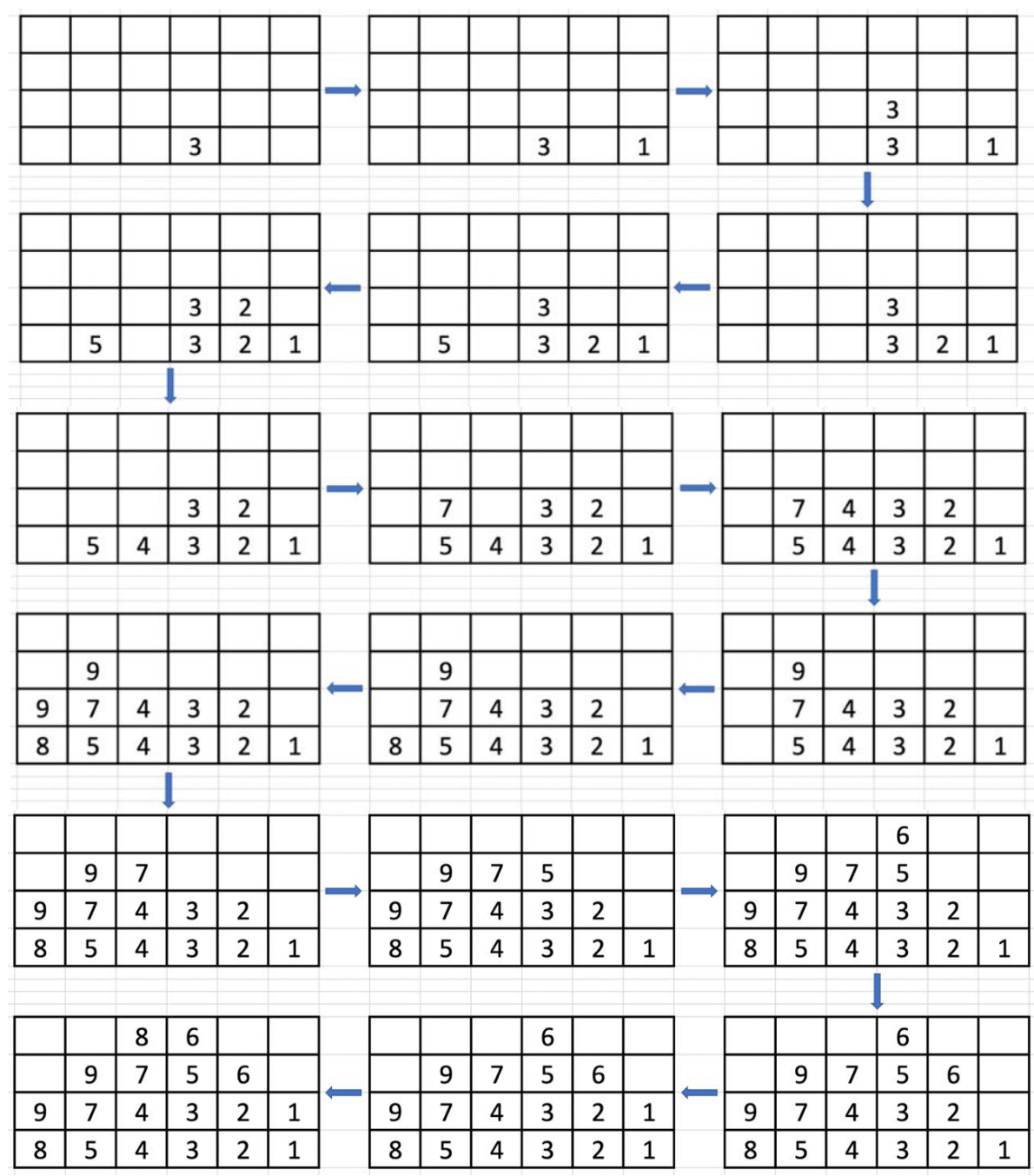

Şekil 7: HDİA algoritması ile sayısal örneğin çözümünün gösterilmesi

\section{Sonuçlar ve Tavsiyeler}

Bir deniz istasyonunda dışarı giden konteynerler için depolama konumu atama problemi direkt olarak yükleme operasyonlarının taşıma verimi ile ilgilidir ve dışarı giden konteynerlerin rasgele gelişinden dolayı bu problemin çözümü zordur. Her bir konteyner için kesin depolama konumu belirlenir. Verilen bir iskelede keyfi bir düzenleme ile bir konteyner için en iyi konum seçimi tanımlanır. Buna dayanarak, her bir konteynerin istasyona varışı üzerine bu konteynerler için depolama konumu belirlemek amacıyla hibrit dizi istifleme algoritması geliştirilmiştir. Çalışmada hibrit dizi istifleme algoritması tanıtılmış ve sayısal bir örnek çözümü sunulmuştur.

Gelecek çalışmalarda hibrit dizi istiflemesi algoritmasına alternatif yeni bir algoritmanın geliştirilmesi planlanmaktadır. Bu yeni algoritma, hibrit dizi istiflemesi algoritması ve rastgele elde edilen çözümler birbirleriyle karşılaştırılacaktır. Mevcut çalışmada algoritmanın performansı tekrar edilen işlem sayısı ile ölçülmektedir. Bu sayı ne kadar az ise algoritma o kadar iyidir. Bu kapsamda 
algoritmaların performansını ölçmede kullanılacak maliyet gibi yeni performans göstergeleri geliştirilecek ve algoritmalar buna göre karşılaştırılacaktır. Geliştirilecek algoritmaların yazılımları geliştirilebilir. Böylece çok sayıda örnek problem çok kısa sürede çözülebilir. Benzetim yazılımları (Arena) kullanılarak daha detaylı çalışmalar yapılabilir.

Ayrıca çalışmada dikkate alınan problemin matematiksel modeli oluşturularak optimizasyonu gerçekleştirilebilir. Yapılan çalışan örnek vakalar ile geliştirilebilir.

\section{Kaynakça}

Chen, L. \& Lu, Z. (2012). The storage location assignment problem for outbound containers in a maritime terminal. International Journal of Production Economics, 135 (1), 73-80.

Castilho, B. \& Daganzo, C.F. (1992). Handling strategies for import containers at marine terminals. Transportation Research, Part B 27, 151-166.

Kim, K.H. \& Kim, H.B. (1999). Segregating space allocation models for container inventories in port container terminal International Journal of Production Economics, 59, 415-423.

Kim, K.H. \& Park, K.T. (2003). A note on a dynamic space allocation method for outbound containers. European Journal of Operational Research, 148 (1), 92-101.

Kim, K.H., Park, Y.M. \& Ryu, K.R. (2000). Deriving decision rules to locate export containers in container yards. European Journal of Operational Research, 124 (1), 89-101.

Zhang, C., Liu, J., Wan, Y.-W., Murty, K.G \& Linn, R.J. (2003). Storage space allocation in container terminals. Transportation Research, Part B 37, 883-903. 